\title{
Light-weight Optimum Design of Laminate Structures of a GFRP Fishing Vessel
}

\author{
Jae-Won Jang®*, Zhiqiang Han $\circledast^{*}$ and Daekyun $\mathrm{Oh}^{\circledast^{* *}}$ \\ "Graduate School, Mokpo National Maritime University, Mokpo, Korea \\ *Department of Naval Architecture and Ocean Engineering, Mokpo National Maritime University, Mokpo, Korea
}

\section{GFRP 낚시어선의 선체구조 적층판 분석과 경량화 설계}

\author{
장재원(** Zhiqiang Han®* 오대균(** \\ *목포해양대학교 대학원 해양시스템공학과 \\ *목포해양대학교 조선해양공학과
}

KEY WORDS: Fishing vessel 어선, Lightweight design 경량화 설계, Ship design 선박 설계, Composite material 복합소재, GFRP 유리섬 유강화플라스틱

\begin{abstract}
Approximately 90,000 ships are registered in South Korea, and about 80,000 of these ships are used in domestic shipping. Among these, 84\% are small ships, such as a fishing vessels that weigh less than 20 tons and are made mostly of an FRP (Fiber Reinforced Plastics). When this fact is taken into account, the greenhouse gas emissions that are released per ton of a composite vessel are sizeable. In this study, the laminated structures of an FRP fishing vessel, many of which currently are being built in Korea, were analyzed by ISO (International Organization for Standardization) and international design rules, and the structures of the hulls are lightweight with optimum glass fiber mass content as determined by the laminate weight minimization algorithm. As a result, it was confirmed that the laminations of the vessels in accordance with the Korean rule could have $6.4 \%$ to approximately $11 \%$ more design margin compared to the requirements of ISO and other international rules. And the case study of the application of the laminate weight minimization algorithm showed the possibility of reducing the weight of the hull bottom plating by as much as about 19.32\% and by as much as about $18.06 \%$ in the overall structure.
\end{abstract}

\section{1. 서 론}

국제해사기구 IMO(International Maritime Organization)는 국제 해운산업에 의한 온실가스(Green house gases, $\mathrm{GHG}$ ) 증가에 따 른 기후변화에 대응하기 위하여 최근까지 다양한 정책과 실행 방안을 채택해 오고 있으며, 2011년에는 신조선에 대한 에너지 효율 설계지수(Energy efficiency design index, EEDI) 및 선박 에 너지 효율 관리계획(Ship energy efficiency management plan, SEEMP)을 강제화하는 해양오염방지협약(International convention for the prevention of marine pollution from ships, MARPOL) Annex VI를 채택하였다(Joung et al, 2018). 하지만 이 협약은 $\mathrm{GT}$ (Gross tonnage) 400톤 이상의 선박을 대상으로 하고 있으며 전체 선박의 절대 다수를 차지하고 있는 소형선박은 제외되어 있는 실정이다. 국내 등록선박 중 $90 \%$ 이상 역시 30 톤 미만의
소형선박이며, 이러한 상황을 고려한다면 저탄소 친환경 소형 선박 개발기술의 시급성 역시 확인할 수 있다.

이러한 소형선박의 환경규제 선대응을 위한 다양한 노력도 있어 왔다. 선체 현대화사업, 어업 윤전제도, 저속운항지역 지 정, 적재량 제한과 같은 제도적인 접근과 전기추진시스템 개발, $\mathrm{LED}$ (Light emitting diode) 집어등 도입과 같은 기술개발도 제안 된 바 있다. 다만 이러한 방법은 환경규제에 적극적으로 대응하기 에는 다소 우회적이고 간접적이라고 할 수 있다(Oh et al, 2019).

소형선박은 일반적으로 유리섬유강화플라스틱(Glass fiber reinforced plastic, GFRP)을 선체소재로 사용하고 있다. GFRP는 건조 와 폐기하는 과정에서 환경문제 유발로 많은 지적을 받고 있지만 소재 특성이 수명이 길고 비강도가 좋으며 부식에도 강하여 환경규 제가 강한 유럽에서도 요트, 어선 등 소형선박의 소재로 널리 사용되 고 있고(Oh, 2019), 국내등록 선박의 약 $87 \%$ 를 차지하고 있는 어선의

Received 21 November 2019, revised 14 December 2019, accepted 19 December 2019

Corresponding author DaeKyun Oh: +82-61-240-7318, dkoh@mmu.ac.kr ORCID: http://orcid.org/0000-0001-5239-1590

It is noted that this paper is revised edition based on proceedings of KAOST 2019 in Jeju.

(c) 2019, The Korean Society of Ocean Engineers

This is an open access article distributed under the terms of the creative commons attribution non-commercial license (http://creativecommons.org/licenses/by-nc/3.0) which permits unrestricted non-commercial use, distribution, and reproduction in any medium, provided the original work is properly cited. 
선체 역시 대부분이 GFRP로 건조되고 있다(MOF, 2016).

본 저자들은 GFRP 선체구조 적층판(Laminate)을 경량화하기 위 한 최적 유리섬유 강화재양의 결정(Song and Oh, 2016), 복합소재 구조의 경량화에 따른 물리적 거동(Oh et al, 2018a) 등에 대한 연구 를 수행한 바 있으며 이러한 연구결과를 토대로 GFRP의 경량화가 GHG 배출량 감소에 미치는 영향에 대한 연구를 수행한 바 있다 (Oh et al, 2018b; Oh et al, 2019). 본 연구에서는 선행연구 결과를 활용하여 최근 건조 수요가 증가하고 있는 GFRP 낚시어선을 대 상으로 GFRP 어선의 선체 경량화 가능성을 확인하고자 하였다. 총톤수(GT) 9.77 낚시어선을 사례연구 대상으로 정의하였으며, 현재 구조 적층판의 설계를 ISO (International Organization for Standardization) 국제표준 및 국제선급 규정과의 비교분석을 통해 사례선박의 설계마진률을 분석하였으며, 선체 외판을 대상으로 경량 최적 유리섬유 강화재 비율, 즉 유리섬유 함침율 $(\mathrm{Gc}, \mathrm{Glass}$ content)을 추정하여 개선된 GFRP 설계안을 도출함으로써 사례선 박의 경량화 가능성을 정량적으로 제시하고자 한다.

\section{2. 어선 선체구조 적층판 분석}

\subsection{FRP 낚시어선 개요}

최근 해양레저활동의 저변 확대와 함께 바다낚시 인구의 증 가로 낚시어선의 수요가 많아지고 있다. 사례선박인 GT 9.77 낚 시어선은 한국해양교통안전공단의 규정(KOMSA, 2019; 이하 Korean 규정)에 따라 개발되었으며 배수량 39.39톤, 전장 $19.1 \mathrm{~m}$, 선속 13 노트 $(24.08 \mathrm{~km} / \mathrm{h})$ 의 소형어선이다. Table 1과 Fig. 1은 선 박의 주요제원과 구조배치를 보이고 있다(RIMS, 2006).

Table 1 Principle particulars of the target ship

\begin{tabular}{ccc}
\hline \hline Item & Value & Unit \\
\hline$L_{O A}$ & 19.10 & $\mathrm{~m}$ \\
$L_{B P}$ & 14.60 & $\mathrm{~m}$ \\
$B_{w l}$ & 4.38 & $\mathrm{~m}$ \\
$\mathrm{D}$ & 1.18 & $\mathrm{~m}$ \\
$\mathrm{~T}$ & 0.80 & $\mathrm{~m}$ \\
$C_{B}$ & 0.621 & - \\
$\triangle$ & 39.39 & $\mathrm{t}$ \\
Speed & 24.08 & $\mathrm{~km} / \mathrm{h}$ \\
\hline
\end{tabular}

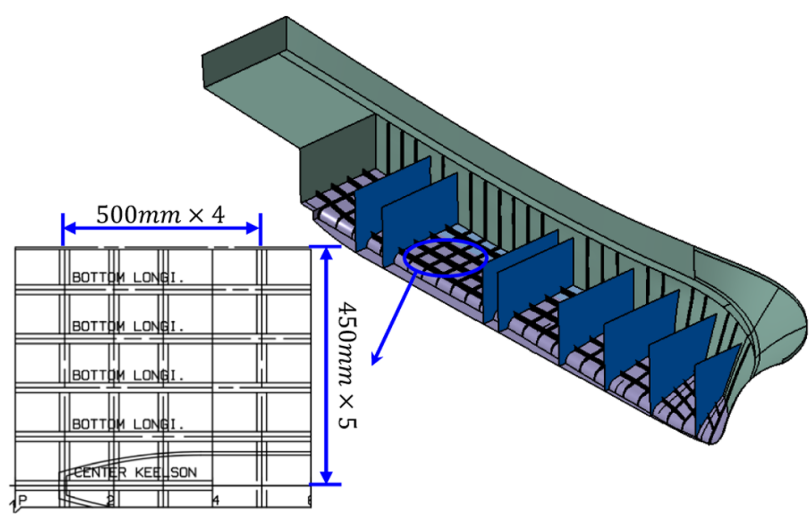

Fig. 1 Structures arrangement and stiffeners lay-out

\subsection{GFRP 구조 원자재의 구성과 적층판 설계}

낚시어선의 구조 적층판을 구성하는 원자재와 적층 스케줄을 분석하였다. 유리섬유강화재(Reinforcement)는 매트(CSM, Chopped strand mat)와 로빙(WR, Woven rving) 두 가지를 섞어서 제작되 었으며, 유리섬유의 단위면적당 중량은 매트와 로빙이 각각 $450 \mathrm{~g} / \mathrm{m}^{2}$ 과 $570 \mathrm{~g} / \mathrm{m}^{2}$ 이었고 기지재(Matrix)는 열경화성 수지 폴리 에스터(Polyester)를 사용하였다. 설계분석 적층판은 일반적으로 가장 큰 하중을 받는 선저판을 대상으로 선정하였다. 선저판의 생산 설계 두께는 $9.14 \mathrm{~mm}$ 였으며, 적층스케줄은 ' $C S M+(C S M+W R)$ $\times 4+C S M$ '이었다. Fig. 2 는 낚시어선의 선저판 적층 스케줄을 도식화하여 보이고 있으며, Table 2는 두 유리섬유와 수지의 물 성정보를 보이고 있다. 선저 적층판의 함침율 $(G c)$ 즉 강화재인 유리섬유의 무게비율(Weight fraction)은 ISO 국제표준(ISO, 2008; 이하 ISO 표준) 식 (1)에 따라 약 $36.7 \%$ 로 분석되었다.

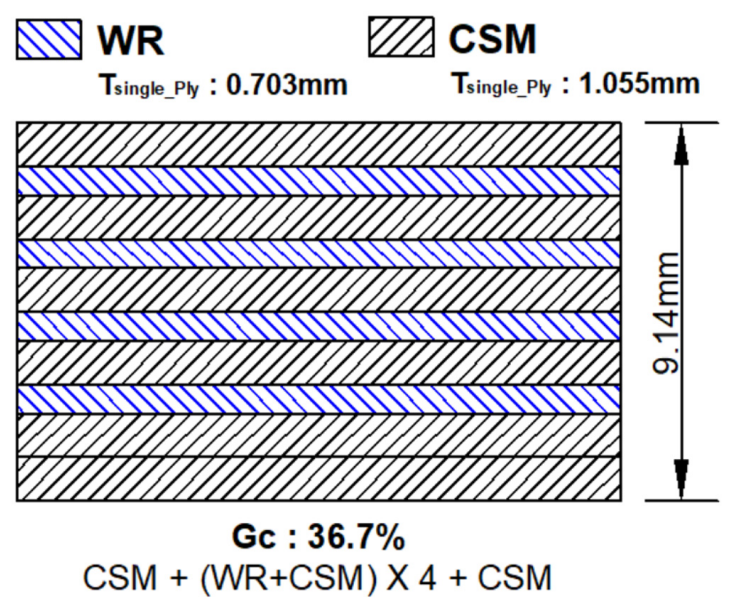

Fig. 2 Laminate schedules for hull plating

Table 2 Raw materials for hull plating

\begin{tabular}{ccccc}
\hline \hline & Item & Value & Unit \\
\hline \multirow{4}{*}{ Material } & $\begin{array}{c}\text { Fiber e-glass } \\
\text { fabric }\end{array}$ & Density & 2.5 & $\mathrm{~g} / \mathrm{m}^{3}$ \\
& & Weight (CSM) & 450 & $\mathrm{~g} / \mathrm{m}^{2}$ \\
\cline { 2 - 5 } & $\begin{array}{c}\text { Polyester } \\
\text { resin }\end{array}$ & Deight (WR) & 570 & $\mathrm{~g} / \mathrm{m}^{2}$ \\
\hline
\end{tabular}

$$
\begin{aligned}
& G c=\frac{p_{1}+p_{2}+p_{3}+\cdots+p_{n}}{\frac{p_{1}}{g c_{1}}+\frac{p_{2}}{g c_{2}}+\frac{p_{3}}{g c_{3}}+\cdots+\frac{p_{n}}{g c_{n}}} \\
& p: \text { Unit weight per area of fabric }\left(\mathrm{kg} / \mathrm{m}^{2}\right) \\
& G c: \text { Glass content in a single ply }
\end{aligned}
$$

\section{3 낚시어선 구조 적층판의 설계마진 분석}

낚시어선의 선체구조 경량화 가능성을 확인하기 위하여 선저 판 설계결과를 국제표준 및 주요 국제선급 규정과 비교분석하 였다. 비교대상으로는 소형선박의 설계건조 ISO 표준(ISO, 2008)과 요트와 같은 소형선박의 인증에 널리 적용되고 있는 RINA(Registro Italiano Navale) 선급규정(RINA, 2013; 이하 RINA 
Table 3 Operating-mode determination by each rule

\begin{tabular}{cccc}
\hline \hline Item & Definition & Target ship & Mode \\
\hline Korean Rule & $\frac{V}{\sqrt{L}}>9$ & & Displacement \\
& $\frac{V}{\sqrt{L}}>5$ & $(24.08 \mathrm{~km} / \mathrm{h})$ & Displacement \\
ISO 12215 & $L_{w l}: 14.066 \mathrm{~m}$ & \\
& $\frac{V}{\sqrt{L}}>4$ & $\frac{V}{\sqrt{L_{w l}}}=3.5$ & Displacement \\
RINA Rule & $\frac{V}{\sqrt{L}}>3$ & & Planing \\
LR Rule & $\frac{V}{2}$ & & \\
\hline
\end{tabular}

$L_{w l}$ : Length on waterline

규정) 그리고 LR(Lloyd's Register) 선급규정(LR, 2018; 이하 LR 규정)을 선정하였다.

선저판의 동일 위치를 대상으로 설계하중과 요구두께를 추정 하였으며, 낚시어선의 생산설계 원안에 적용된 생산설계 마진 을 동일하게 적용하였을 때, 이 때 각 규정의 설계결과에 따른 단위면적당 무게를 비교분석하였다.

선저판에 작용하는 설계하중을 추정하기 위하여 각 규정에 따라 선속에 따른 항행타입을 분석하였다(Table 3). LR 규정의 경우 선박이 다소 활주할 수 있다고 판단하고 있으며 나머지 규정에서는 배수량형으로 판단하고 있었다. Fig. 3은 종방향 설 계하중추정 결과를 도식화하여 보이고 있다. Korean 규정의 경 우 구획설계결과에 따른 종방향 설계하중의 계산법을 제시하지 않고 있으며, ISO 표준과 RINA 규정의 경우 수두압과 종방향 낙하가속도를 고려하고 있었고, LR 규정의 경우 활주로 인한 충격하중이 추가로 고려되고 있었다.

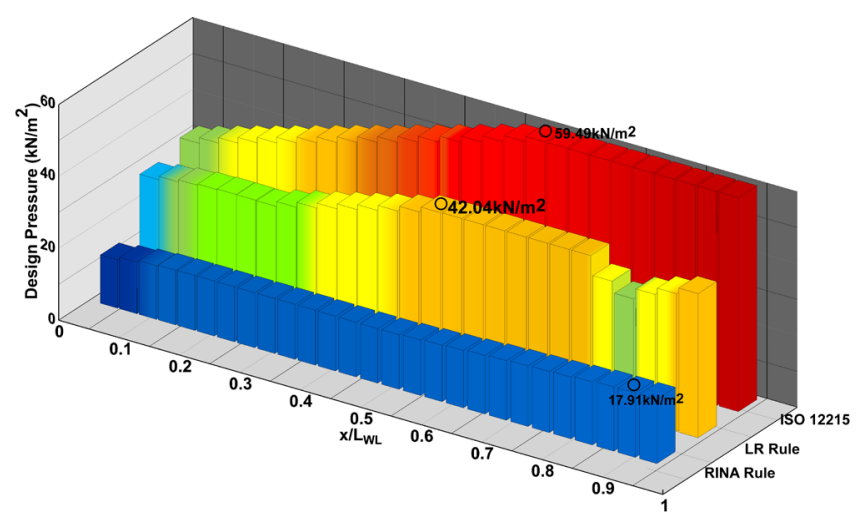

Fig. 3 Longitudinal design pressure acting on bottom plate

Table 4 Comparisons on mechanical properties estimations by each rule

\begin{tabular}{ccc}
\hline \hline Item & $\begin{array}{c}\text { Tensile strength } \\
\left(\mathrm{N} / \mathrm{mm}^{2}\right)\end{array}$ & $\begin{array}{c}\text { Flexural strength } \\
\left(\mathrm{N} / \mathrm{mm}^{2}\right)\end{array}$ \\
\hline Korean Rule & $98^{(\mathrm{a})}$ & $148^{(\mathrm{a})}$ \\
ISO 12215 & 115 & 175 \\
RINA Rule & 108 & 175 \\
LR Rule & 119 & 175
\end{tabular}

(a) : The value is low bound through material test required by Korean rule
하중에 따른 요구두께를 계산하기위해서는 GFRP의 강도 추 정이 필요한데, 이를 위해서는 적층판의 함침율 $(\mathrm{Gc})$ 을 필요로한 다. 각 설계규정에서 제시하고 있는 물성 추정식에 앞서 얻은 선저판의 평균 함침율 $36.7 \%$ 를 적용하여 Table 4 와 같은 물성을 도출할 수 있었다. Korean 규정의 경우 다른 규정보다 GFRP의 인장 및 굽힘강도와 같은 기계적 물성을 다소 낮게 추정하는 것을 확인할 수 있었으며, ISO 표준과 RINA 규정, LR 규정은 비슷한 경향을 보이고 있는데 이는 두 선급규정이 ISO 표준에 기반하고 있기 때문인 것으로 판단된다.

각 규정의 설계하중 및 물성추정 결과에 따라 선저판의 요구 두께와 설계두께를 비교함으로써 낚시어선의 설계마진을 분석 하였다. Table 5 는 각 규정의 요구두께 추정식을 요약하여 보이 고 있으며, Fig 4는 낚시어선 설계원안의 두께를 포함한 요구두 께 및 설계두께의 결과를 보이고 있다.

ISO 표준과 RINA, LR 규정은 선형의 형상, 구조배치의 결과 에 따른 설계면적의 형상 조건 그리고 종방향 낙하 가속도 등 을 고려하고 있었으나, Korean 규정은 주요 설계조건에 의해 요 구두께를 산출하고 있었다. 각 규정에 따른 FRP 적층판의 물성 추정에 대한 비교 분석은 다음 장에서 자세히 다루었다.

Table 5 Formulas to calculate required thickness of lamination

\begin{tabular}{cc}
\hline \hline Item & Required thickness formulas \\
\hline Korean rule & $T=15.80 \times s \times(d+0.026 \times L)^{0.5}$ \\
ISO 12215 & $T=s \times K_{C} \times\left(\frac{\left(P \times K_{2}\right)}{\left(1000 \times 0.5 \times \sigma_{u f}\right)}\right)^{0.5}$ \\
RINA rule & $T=K_{1} \times s \times P^{0.5} \times K_{a} \times\left(152 / \sigma_{u f}\right)^{0.5}$ \\
LR rule & $T=0.146 \times s \times\left(P / E_{t p s}\right)^{1 / 3}$ \\
\hline
\end{tabular}

$s:$ Short dimension of design area

$d$ : Full load draft, in $\mathrm{m}$

$L$ : Full load waterline length, in $\mathrm{m}$

$\mathrm{P}$ : Design pressure, in $\mathrm{kN} / \mathrm{m}^{2}$

$\sigma_{u f}:$ Flexural strength, in $\mathrm{N} / \mathrm{mm}^{2}$

$K_{C}$ : Curvature correction factor for curved panels

$K_{1}:$ Coefficient by design pressure type

$K_{2} \& K_{a}$ : Panel aspect ratio factor

$E_{t p s}$ : Tensile modulus of elasticity

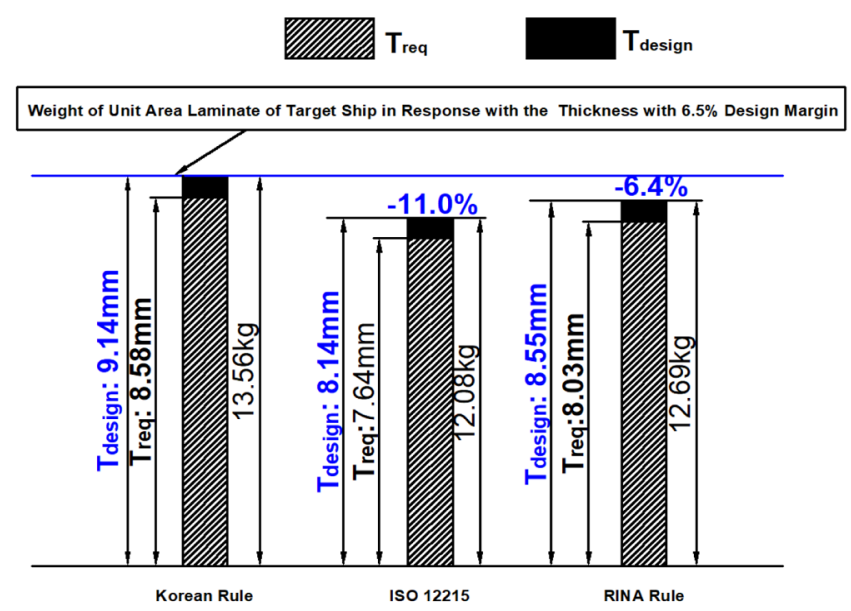

Fig. 4 Design margin analysis : comparison of required thickness and design thickness by each rule 
ISO 표준과 RINA, LR 규정의 경우, 최대 설계하중이 작용 (Fig. 3)하는 지점에서의 요구두께를 비교분석 대상으로 정의하 였다. 각 규정에서 도출된 요구두께에 낚시어선에 적용된 생산 마진 $6.5 \%$ 를 일괄로 적용하여 각 규정에 의한 이론적인 설계두 께를 산출하였다. LR 규정의 경우는 앞서 언급한 것과 같이 주 어진 속력조건에서 낚시어선이 활주하는 선박으로 판단하고 있 기 때문에 충격하중을 추가로 고려하고 있고 이에 따라 상당한 외판두께를 요구하고 있기 때문에 적층판의 설계마진 비교분석 에서 제외하였다.

산출된 설계두께의 무게는 ISO 표준에서 제시하고 있는 식 (2)에 따라 추정하였으며, 세 가지 규정에 의한 낚시어선의 선 저판의 요구두께와 설계두께 그리고 무게의 비교분석결과는 Fig. 4와 같았다. Korean 규정에 의한 설계두께와 무게는 ISO 표 준과 RINA 규정보다 각각 $11 \%$ 와 $6.4 \%$ 더 큰 것으로 분석되었 다. 이는 ISO 표준과 RINA 규정은 Korean 규정보다 다양한 조 건에 의해 설계하중을 추정하고 있어 다소 큰 설계하중 추정의 결과를 보였으나, 설계면적의 종횡비율, 종방향 설계하중 분포, 낙하 가속도 등 선형의 형상과 구조의 배치결과를 추가 고려함 으로써 요구두께를 줄일 수 있는 여지가 있는 것으로 판단되었 다. 또한 Korean 규정이 적층판의 물성추정을 다소 낮게 추정한 결과도 설계마진의 차이를 키우는 결과의 원인으로 분석되었다. 적층판 설계를 위한 네 가지 규정은 Fig. 5에 비교분석하여 도 식화 하였다.

$$
W_{\text {laminate }}=\frac{\left(\rho_{F} \times \rho_{R} \times T\right)}{\left(\rho_{F}-\left(\rho_{F}-\rho_{R}\right) \times G c\right)}
$$

$\rho_{F}:$ Density of fabric $\left(\mathrm{kg} / \mathrm{m}^{3}\right)$

$\rho_{R}:$ Density of resin $\left(\mathrm{kg} / \mathrm{m}^{3}\right)$

\section{3. 복합소재 선체구조 적층판 경량화 알고리즘}

낚시어선의 선저판 설계를 ISO 표준 및 국제선급 규정과 비 교분석 함으로써 타 규정 대비 설계마진률을 분석하였다. 이번 장에서는 본 연구자들의 선행연구 결과인 복합소재 선체구조 적층판 경량화 알고리즘(Song and Oh, 2016; Oh et al, 2018a)을 선저판 설계에 적용함으로써 경량화 개선된 GFRP 설계안을 도 출하고자 하였다.

일반적으로 복합소재 선체구조 적층판의 두께를 결정하는 변 수는 배수량, 선속, 구획 및 보강재의 배치, 설계하중과 같은 선 박설계 요소와 복합소재의 설계조건에 의해 결정된다. 소재설 계 조건은 강화재의 종류, 직물의 직조방식, 함침율에 따른 선 저판의 기계적 물성 등에 따라 결정된다(Oh et al, 2014). 본 연 구에서는 낚시어선의 선형과 구획배치 등을 변화시키지 않고, 설계원안에 적용된 유리섬유 강화재의 비율 즉 함침율 $(\mathrm{Gc})$ 을 최적화하여 선체구조 적층판의 경량화를 시도하였다.

복합소재 적층판 경량화 알고리즘은 선체구조의 종류 및 섬 유의 직조방식 등에 따라 적층판의 구조안정성을 확보하고 단 위면적 당 무게를 최소화하는 함침율을 결정하는 소재설계 알 고리즘이다. 이 알고리즘을 적용하여 적층판의 최적의 함침율 을 찾기 위해서는 함침율 변화에 따른 적층판의 기계적 물성변 화 추정식을 필요로 한다. 적층판의 물성 추정식은 재료시험을 통하여 얻을 수도 있고 소형선박의 설계규정이 제시하는 함침 율 변화에 따른 물성 추정식을 적용할 수도 있다. 본 연구에서 는 각 규정에서 제시하고 있는 물성 추정식을 알고리즘에 활용 하였으며, 네 가지 규정에서 제시하고 있는 적층판의 물성 추정 결과를 함침율 변화에 따라 도식화하여 보이면 Fig. 6과 같다.

ISO 표준 및 국제선급 규정에서는 함침율의 변화에 따라 적

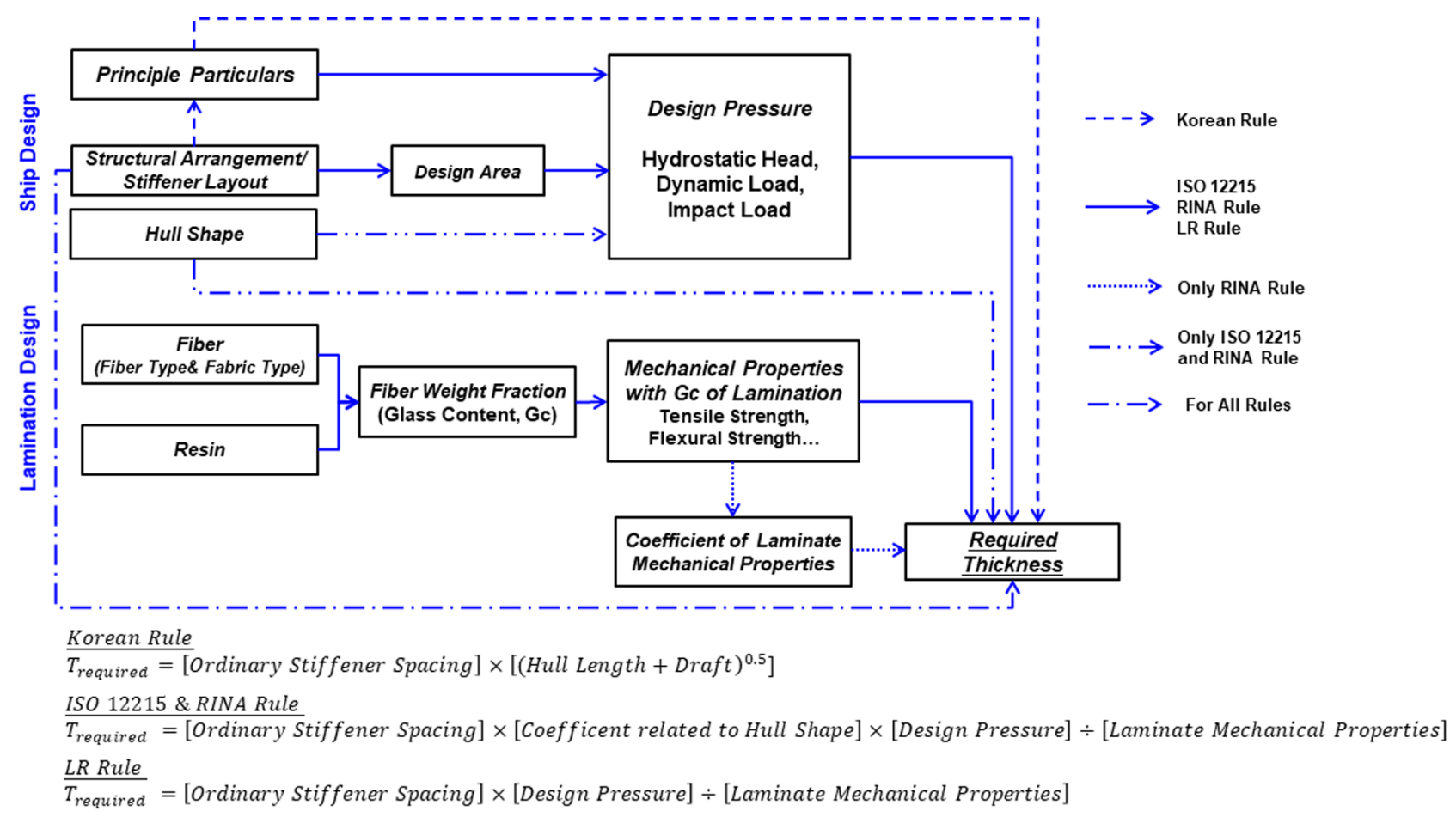

Fig. 5 Comparison of lamination design processes by each rule 
층판의 물성변화를 두께 추정(Table 5)에 고려하고 있으나 Korean 규정은 이를 반영하고 있지 않음을 확인할 수 있었다. 함침율이 증가할수록 적층판의 물성은 증가하는 경향을 보이고 있으며 이러한 경향을 고려하여 적층판을 설계한다면 적층판의 요구두께를 감소시킬 수 있다. 하지만 이는 물성추정식에 따른 이론적인 경향이며 함침율 변화에 따른 적층판의 파괴실험 결 과에 따르면 $60 \sim 70 \%$ 이상의 고함침율에서는 박리현상이나 생 산품질 저하 등에 따라 휨강도가 감소하는 경향을 보인다(Han et al, 2018). 따라서 선형이나 구조배치 등의 선박설계 조건 변 화 없이 적층판을 경량화하기 위해서는 주어진 소재설계 조건 하에서 함침율의 변화에 따른 요구두께 변화량의 상관관계를 고려할 필요가 있는데, ISO 표준 및 국제선급 규정에서는 소재 설계의 조건에 따른 이러한 상관관계를 고려할 수 있는 계수를 제시하고 있다. ISO 표준, RINA, LR 규정에서 제시하고 있는 소재설계 조건에 따른 두께감소 변화계수 사례를 정리하면 식 (3)과 같다. 소재의 조건은 강화섬유의 종류, 직물의 직조방식, 선체구조의 종류 등이 될 수 있으며 이러한 소재 조건의 변화 와 함침율 변화에 따라 두께감소 변화가 달라지기 때문에 이와 같은 계수를 함침율의 함수로 정의하고 있다. 아래 식 (3)은 소 재설계조건이 유리섬유 강화재로 단일적층판(Single-skin)을 제 작할 때의 두께감소 변화계수를 규정별로 보이고 있다. 유리섬 유 강화재의 경우 매우 일반적으로 사용되기 때문에 매트(CSM) 와 로빙(WR) 직물 구분없이 같은 계수로 제시되고 있다.

국제규정에서는 유리섬유 강화재가 $30 \%$ 이상 포함되어야 해 양복합소재로 유효하다고 정의하고 있기 때문에 함침율 $(G c)$ 은 0.3 이상부터 고려되고 있으며, 식 (3)에서도 이와 같이 함침율 변화에 따라 두께감소 변화계수를 제시하고 있다. RINA 규정의 경우 함침율이 $70 \%$ 이상 되어도 더 이상 두께 감소 계수가 적 용되지 않는 것을 확인할 수 있다.

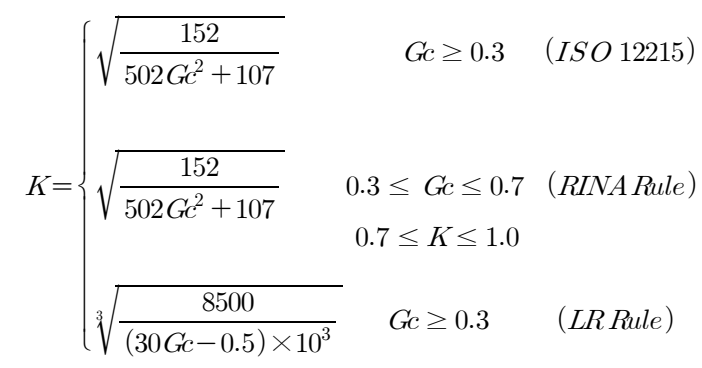

\section{$K:$ Thickness decrement coefficient}

Gc : Glass content in laminate

즉, 앞장에서 설명한 적층판 설계 프로세스(Fig. 5) 중에 함침 율 변화에 따른 물성 변화와 두께감소 변화 계수를 고려하면 적층판의 요구두께를 최소화할 수 있는 함침율을 찾을 수 있다. 여기에 선체 제작에 사용 할 강화재와 수지의 비중, 직물의 단 위면적 당 무게 등 소재설계 조건을 추가로 고려하면 적층판의 무게를 최소화할 수 있는 GFRP 설계안을 도출할 수 있다. 물론 국제규정 등에서 제시하고 있는 이러한 두께감소 변화계수를 최적 함침율 추정에 활용해도 되지만, 건조하고자 하는 선박에 적용되는 직물로 함침율 변화에 따른 적층판의 시제품 제작을 제작하여 파괴시험 등의 결과를 활용한다면 보다 정확하고 실 질적인 최적화 결과를 얻을 수도 있다.

본 연구에서는 적층판 분석에 적용한 국제선급 규정 중 RINA 규정에서 제시하는 정보를 사용하여 낚시어선의 선체외판 $\mathrm{GFRP}$ 를 경량화하기 위한 알고리즘을 재정의하였다. 식 (3)에서 볼 수 있듯이, ISO표준의 경우 함침율 증가에 따라 두께감소율 이 감소하나 무한히 감소하기 때문에 제외하였고, LR 규정의 경우 재료시험 결과를 추가로 필요로하기 때문에 제외하였다.

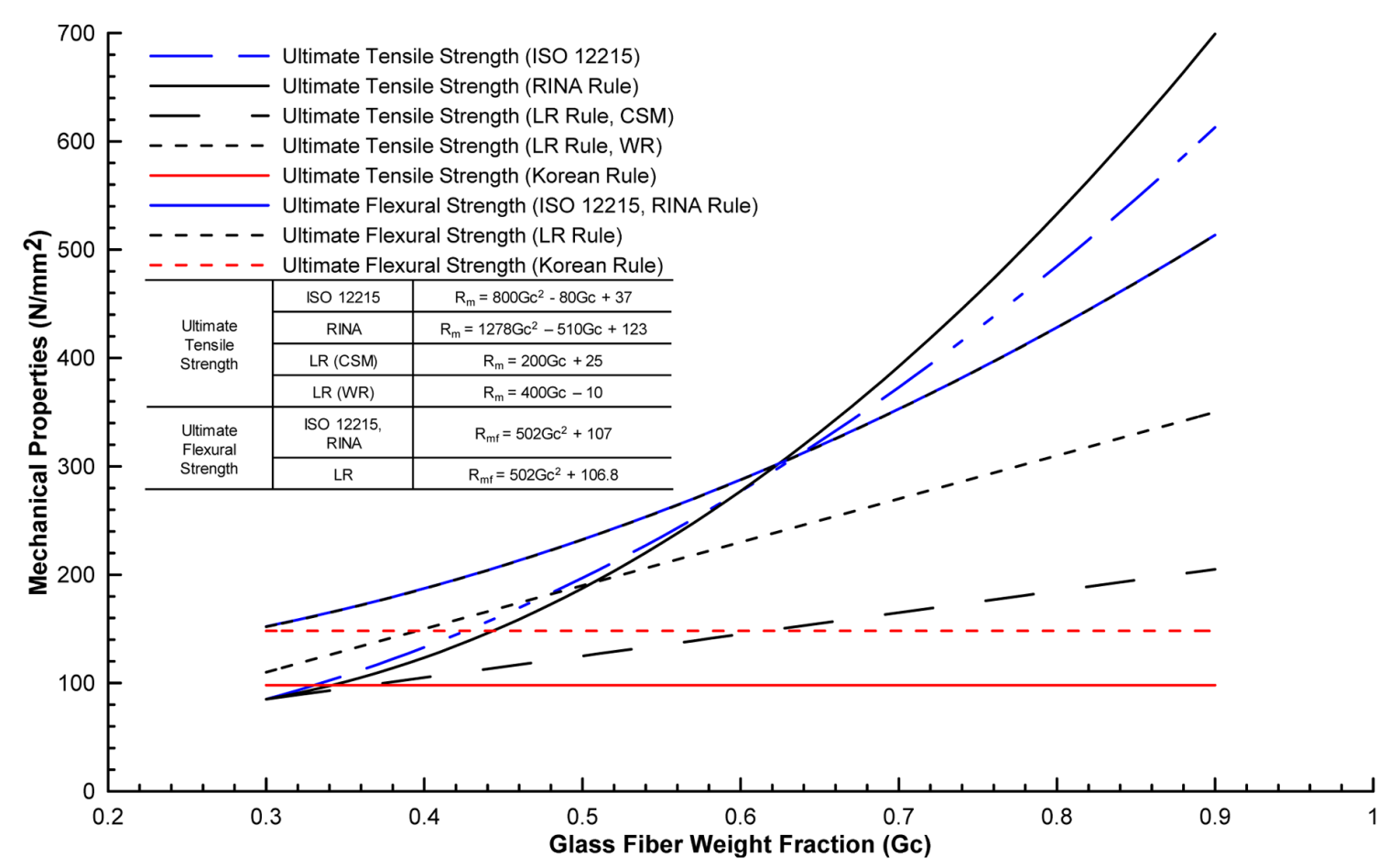

Fig. 6 Mechanical properties with change in glass fiber weight fraction of laminate 


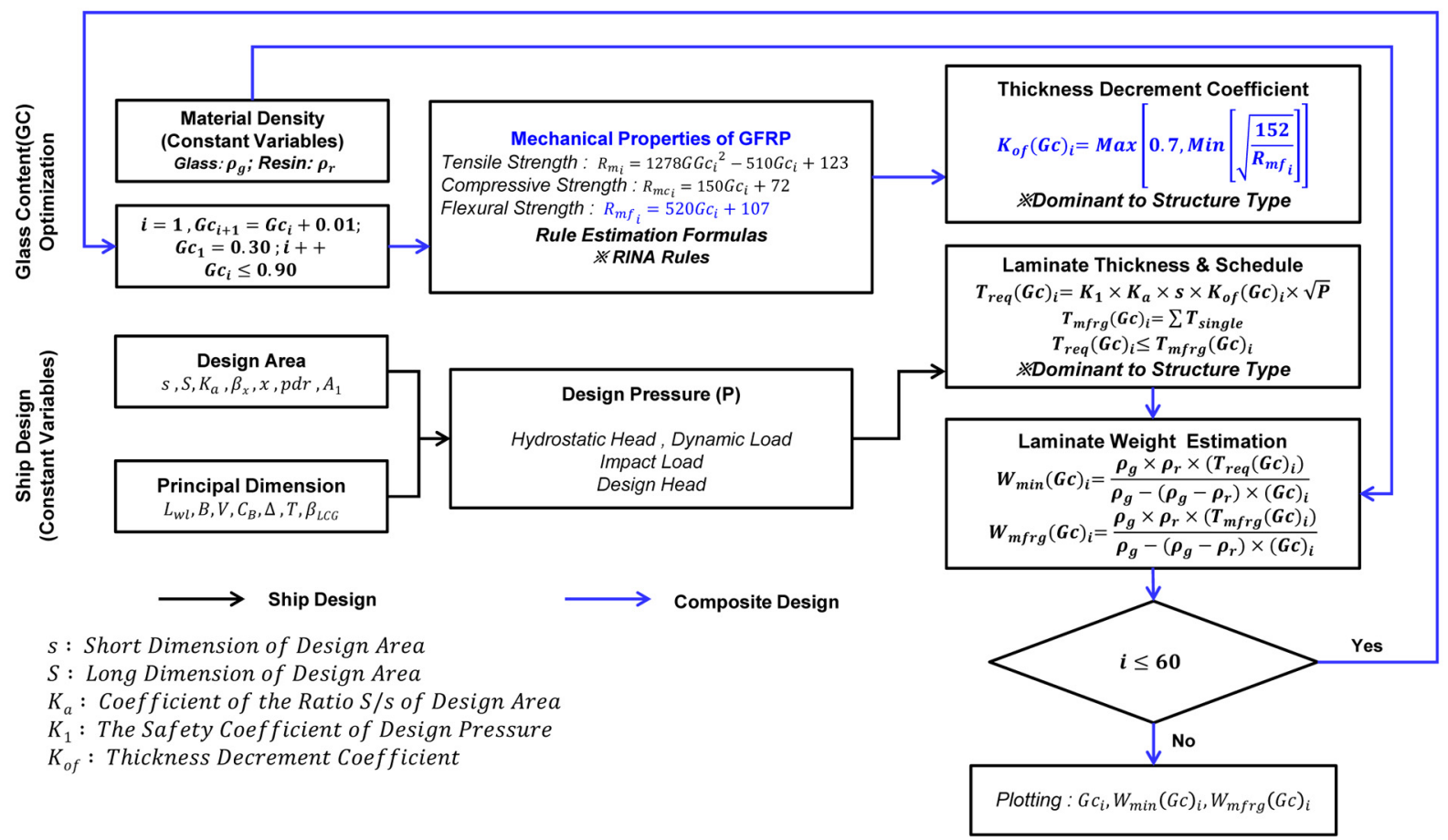

Fig. 7 GFRP lamination weight optimization algorithm for target ship

알고리즘을 세부적으로 정의하기 위하여 RINA 규정에서 제시 하고 있는 인장강도 $\left(R_{m}\right)$ 와 굽힘강도 $\left(R_{m f}\right)$ 추정식, 두께감소 계 수 $\left(K_{o f}\right)$, 적층판 무게 추정식 $\left(W_{(G c)}\right)$ 등을 인용(Fig. 6 및 식 (3)) 하였으며 함침율 변화량을 $30 \%$ 에서 $90 \%$ 까지 $1 \%$ 씩 변화시켰 다. 이렇게 정리한 낚시어선의 선체외판 경량화를 위한 알고리 즘을 정리하여 도식화하면 Fig. 7과 같다.

\section{4. 낚시어선 구조 적층판 경량화 설계}

\section{1 소재설계와 직물적층 조건의 정의}

낚시어선의 경량화 설계안은 동일한 선형과 구조배치 그리고 이에 따른 설계하중을 적용하였다. 유리섬유와 수지의 밀도는 낚시어선 건조 시에 사용된 실제 소재의 밀도인 $2.5 \mathrm{~g} / \mathrm{cm}^{3}$ 과 $1.2 \mathrm{~g} / \mathrm{cm}^{3}$ 을 사용하였으며, GFRP 경량화 시에는 보강재와 데크 및 격벽에 사용된 탑햇(Top-hat)과 샌드위치(Sandwich)구조는 이 미 경량화를 위한 구조형태이기 때문에 경량화 대상에서 제외 하였다.

도출된 최적 함침율을 적용하여 적층판의 무게를 계산하기 위해서는 직물의 적층 스케줄을 포함하는 생산설계를 재실시 해야한다. 즉 설계원안함침율의 변화에 따라 낚시어선의 적층 스케줄 원안(Fig. 2)에서 매트(CSM)와 로빙(WR)을 추가 또는 삭 제하는 적층 스케줄에 대한 가정을 정의해야하는데, 함침율이 감소되는 경우 중간의 매트와 로빙 조합에서 로빙, 매트 순으로 한 장씩 제거하고 함침율이 증가하는 경우 매트를 한 장씩 추 가하는 것으로 정의하였다. 이는 함침율이 감소되는 경우 상대 적으로 유리섬유의 중량이 큰 로빙(WR)을 먼저 제거하도록 하 였고, 함침율이 증가되는 경우 중량이 작은 매트 $(\mathrm{CSM})$ 를 추가 하도록 한 것이다.

\section{2 선체외판 경량화 함침율 추정과 적층판 설계}

최대 하중 $\left(17.91 \mathrm{kN} / \mathrm{m}^{2}\right)$ 이 작용하는 선체 외판의 설계면적을 대상으로 앞서 정의한 알고리즘을 적용하여 최적 함침율을 추 정한 결과 Fig. 8과 같은 결과를 얻을 수 있었다. Fig. 8에서 실 선은 대상 설계면적에 함침율이 증가됨에 따라 변화되는 적층 판의 요구두께 변화를 도식화한 것이며, 범례 의 'Original Case'와 'RINA Rule'은 각각 설계원안과 RINA 규정에 의한 설 계안을 나타내고 있다. 함침율이 증가함에 따라 이론적으로는 약 $64 \%$ 이후에서 요구두께가 급격히 수렴되는 것으로 나타났 으며 그때의 최소 요구두께는 $6.02 \mathrm{~mm}$ 였다. Fig. 8 에서 범례 는 요구두께를 충족시킬 수 있는 적층판의 실 생산두께를 표현 하고 있는데, 실제 생산 가능한 최소 생산두께는 함침율 $80 \%$ 에 서 $6.04 \mathrm{~mm}$ 로 추정되었다.

하지만 적층판의 무게를 최소화하는 함침율을 얻기 위해서는 Fig. 8을 단위면적당 적층판의 무게변화로 변환해야하는데, 이

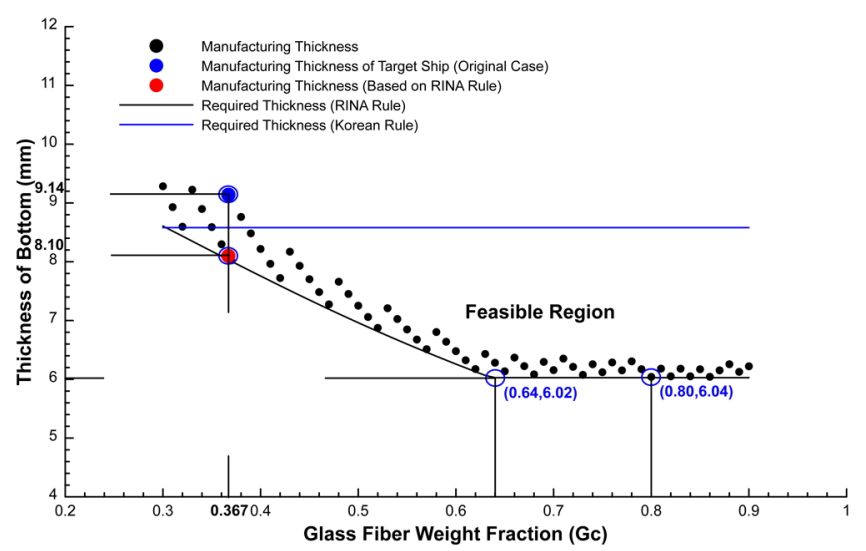

Fig. 8. Lamination thickness with change in $\mathrm{Gc}$ 


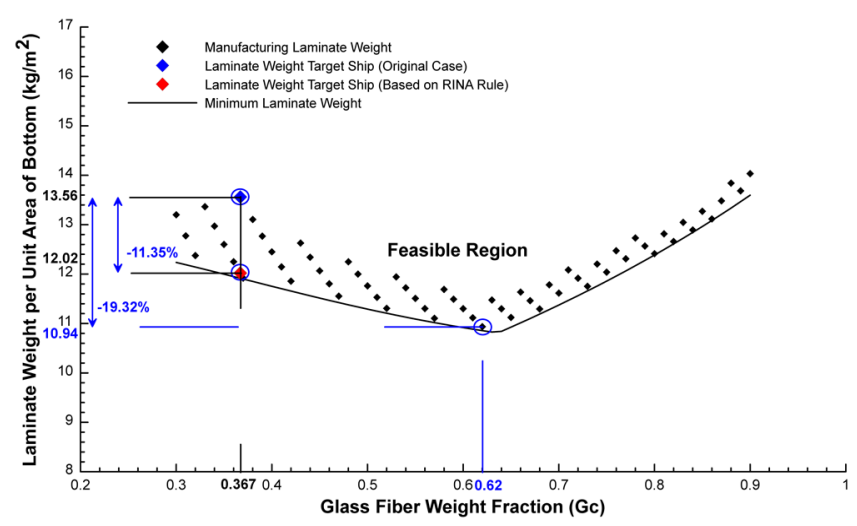

Fig. 9. Optimum Ge to minimize lamination weight

때 설계원안에 해당되는 적층 스케줄에 앞서 정의한 직물 적층 조건을 적용하여 함침율 변화에 따른 적층판 생산설계 결과를 단위면적당 무게변화로 변환이 필요하며 이를 도식화한 결과는 Fig. 9와 같았다. 이때 범례 는 요구두께를 충족시킬 수 있는 매트와 로빙 직물의 적층 조합으로 계산된 단위면적당 적층판 의 무게를 나타내고 있다. Fig. 8 에서는 함침율 $64 \%$ 이후 요구 두께가 급격히 수렴하는 것으로 나타났지만 무게는 함침율 $62 \%$ 직물적층 조합에서 최소가 발생하는 것으로 도출되었다. 이는 함침율 $62 \%$ 이후에서 적층판의 두께를 조금 더 감소시킬 수는 있으나 수지보다 상대적으로 큰 비중을 갖고 있는 유리섬 유의 무게비율이 크게 증가되면서 적층판의 무게도 급격히 증 가하기 때문인 것으로 판단된다.

낚시어선의 선체외판을 경량화 설계한 결과 단위면적당 적층 판의 무게를 최소화할 수 있는 함침율은 $62 \%$ 로 도출되었으며 이때 적층판의 단위면적당 무게는 $13.56 \mathrm{~kg}$ 에서 $10.94 \mathrm{~kg}$ 으로 경 량화가 가능함을 확인하였다. 경량화 설계안대로 적층판을 생 산하기 위해서는 기존 적층스케줄에 $450 \mathrm{~g} / \mathrm{m}^{2}$ 매트(CSM) 4장을 외판에 추가하고 수지의 무게비율을 $63.3 \%$ 에서 $38 \%$ 로 낮추는 $\mathrm{GFRP}$ 생산설계안 ' $C S M \times 5+(C S M+W R) \times 4+C S M$ '을 얻었을 수 있었다. Fig. 10 은 설계원안의 적층스케줄과 함침율 최적화 후의 적층스케줄을 비교하여 보이고 있다.

\section{3 최적 함침율에 의한 선체구조 경량화 효과}

최적 함침율 $62 \%$ 에 의한 선체구조의 경량화 효과를 분석하기 위하여 설계원안의 요구두께, 생산두께 그리고 적층판 무게를 경량화설계안과 각각 비교하였다. 또한 경량화 설계안의 생산 두께가 Korean 규정의 요구를 충족시키지 못하고 있기 때문에 (Fig. 8) 최적화에 적용한 RINA 규정에 맞춰 설계원안 함침율 $36.7 \%$ 로 역설계한 선체 외판의 요구두께, 생산두께 그리고 적

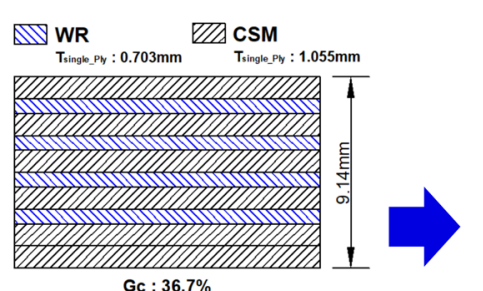

Gc : $36.7 \%$
$\operatorname{CSM}+($ WR + CSM $) \times 4+\operatorname{csM}$

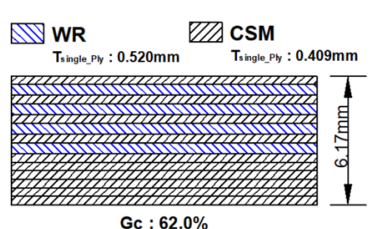

Gc: $62.0 \%$
$\operatorname{cSM} \times 5+(\mathrm{WR}+\mathrm{CSM}) \times 4+\mathrm{CSM}$
Fig. 10 Laminate schedules with original case and optimum case

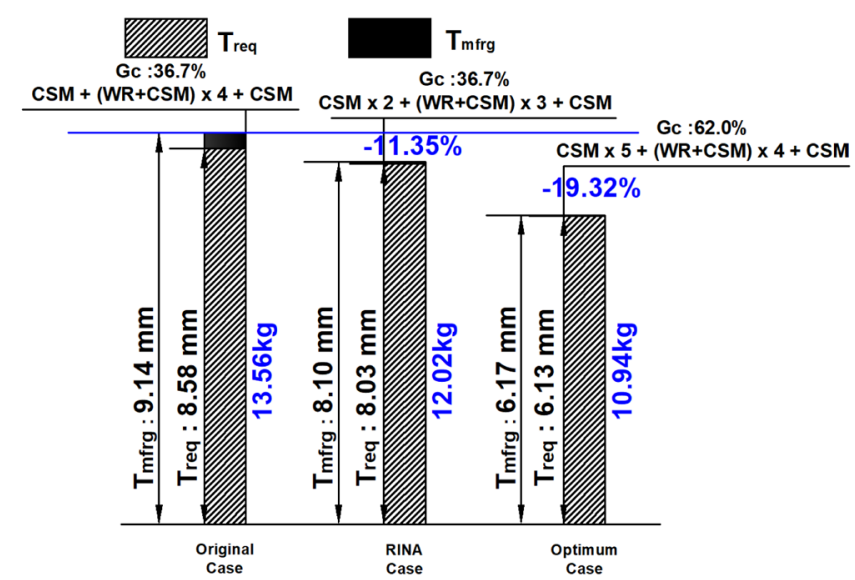

Fig. 11 Comparisons of thickness and weight of bottom plating

Table 6 Structural weight comparisons

\begin{tabular}{cccc}
\hline \hline \multirow{2}{*}{ Structures } & \multicolumn{3}{c}{ Weight $[\mathrm{kg}]$} \\
\cline { 2 - 4 } & Original case & RINA case & Optimum case \\
\hline Bottom & 777.58 & 689.27 & 627.34 \\
Side & 1061.86 & 940.48 & 812.05 \\
Deck & 991.10 & 585.45 & 537.21 \\
Bulkhead & 379.41 & 379.41 & 379.41 \\
Top-hat & 1517.85 & 1517.85 & 1517.85 \\
\hline Total & 4727.80 & 4112.46 & 3873.86 \\
\hline
\end{tabular}

층판 무게를 추가로 비교하였다. 그림 Fig. 11에서 볼 수 있듯 이, 설계원안 대비 단위면적당 적층판의 무게가 약 $19.32 \%$ 경량 화 된 것을 확인할 수 있었고, RINA 규정 설계안의 경우도 약 $11.35 \%$ 경량화가 가능한 것으로 확인되었다.

데크와 격벽 그리고 보강재를 포함하는 선체구조의 총 중량변 화를 비교하기 위하여 설계원안에 따라 $3 \mathrm{D} \mathrm{CAD}$ 모델을 구축하였 다. 이때 함침율 변화에 따른 전체적인 무게변화를 비교하기 위하 여 데크와 격벽을 단일적층판으로 주어진 함침율에 따라 재설계 하였다. RINA 규정안과 경량화설계안에 대하여 각각 CAD 모델 을 수정하였으며, 구조별 중량을 각각 그루핑(Grouping)하여 중량 변화를 비교한 결과는 Table 6과 같았다. 경량화설계안은 설계원 안 보다 $18.06 \%$, RINA 규정안보다 $5.8 \%$ 경량화 효과가 있는 것으 로 시뮬레이션되었다.

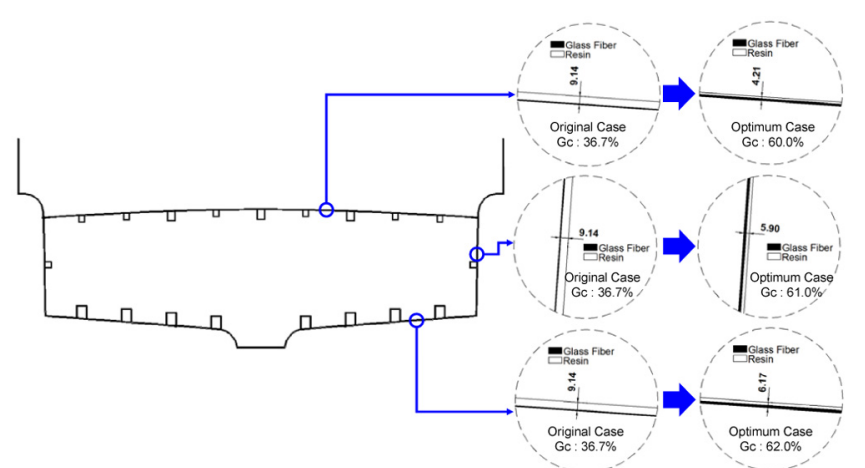

Fig. 12 Comparison of lamination thickness and Gc of original and optimum case at midship-section 
Table 7 Comparisons of longitudinal strength evaluation results

\begin{tabular}{cccc}
\hline \hline Item & Original case & RINA case & Optimum case \\
\hline $\begin{array}{c}\text { Bending stress } \\
{\left[\mathrm{N} / \mathrm{mm}^{2}\right]}\end{array}$ & 18.7 & 23.24 & 29.09 \\
$\begin{array}{c}\text { Allowable stress } \\
{\left[\mathrm{N} / \mathrm{mm}^{2}\right]}\end{array}$ & 26.89 & 26.89 & 40.50 \\
$\begin{array}{c}\text { Bending stress/ } \\
\text { Allowable stress }\end{array}$ & 30.38 & 13.16 & 28.17 \\
{$[$ Safety margin, \%] } & & & \\
\hline
\end{tabular}

함침율 변화에 따른 구조 적층판의 두께변화로 인한 구조안 정성을 확인하기 위하여 최적화에 적용한 RINA 규정에 따라 선체종강도 평가를 진행하였으며, 선체외판 뿐만 아니라 데크 또한 앞서 구조중량 추정 시 재설계한 결과를 고려하여 종강도 평가를 각각 수행하였다. 경량화에 따른 단면의 형상변화는 Fig. 12 와 같았으며, 설계원안과 경량화설계안의 두 함침율에 따른 두께 변화를 유리섬유와 수지의 양적 변화와 함께 도식화하여 보이고 있다. 선체외판의 두께가 약 $33 \%$ 감소되는 등 경량화설 계안의 구조치수 감소로 인해 선체 중앙부에서의 단면계수가 약 $26 \%$ 감소하였고, 이로 인하여 굽힘응력이 약 $29.09 \mathrm{~N} / \mathrm{mm}^{2}$ 로 상승하였지만 함침율의 증가에 따른 적층판의 허용응력이 $40.50 \mathrm{~N} / \mathrm{mm}^{2}$ 로 상승함으로써 경량화설계안의 허용응력에 대한 굽힘응력 비는 유사한 수준을 나타내었다(Table 7). 최대 굽힘응 력 지점(데크)에서의 종강도 평가결과는 판별식 (4) (RINA, 2013)에 따라 경량화설계안 또한 문제가 없음을 확인하였다.

$\sigma_{h}<f \cdot \sigma_{i}$

$\sigma_{h}:$ The most bending stress $\left(\mathrm{N} / \mathrm{mm}^{2}\right)$

$f$ : Safety factor. Displacement craft $=0.25$

$\sigma_{i}:$ The lesser of the values of ultimate tensile and compressive strength of laminate $\left(\mathrm{N} / \mathrm{mm}^{2}\right)$

$f \cdot \sigma_{i}:$ Allowable stress

\section{5. 결 론}

본 연구에서는 최근 많은 수요가 있는 FRP 낚시어선을 대상 으로 구조 적층판의 소재설계를 분석하였고 복합소재 적층판 경량화 알고리즘을 적용하여 경량화설계안을 제시함으로써 FRP 어선의 경량화 가능성을 정량적으로 시뮬레이션 하였다.

이를 위해 GT 9.77 낚시어선의 선체구조 적층판을 구성하는 원자재와 적층 스케줄을 ISO 표준과 국제규정들과 비교분석하 였고, 그 결과 선체 외판을 기준으로 설계원안 적층판에는 약 $6.4 \% ~ 11 \%$ 의 설계마진이 추가로 존재하고 있음을 확인하였다.

낚시어선의 구조 적층판을 경량화하기 위하여 본 선의 건조 에 사용된 원자재와 RINA 규정에서 제시하고 있는 식을 중심 으로 적층판 경량화 알고리즘을 재정의 하였고 이를 적용하여 선저판 기준 최대 $19.32 \%$, 선체구조 기준 최대 $18.06 \%$ 의 경량 화가 가능함을 확인하였다.

연구결과를 통하여 복합소재 어선의 경량화 향상을 위한 규
정의 개선방향을 비교분석할 수 있었으며, 기존에 널리 사용되 고 있는 GFRP 생산설계안의 개선 필요성도 확인할 수 있었다. 이러한 FRP 어선의 적층판 경량화 설계방안을 활용한다면 최근 이슈가 되고 있는 소형선박의 배출가스 감축에도 활용 가능할 것으로 판단된다. 하지만 좀 더 정확한 경량화 시뮬레이션을 위 해서는 본 선에 적용된 직물을 대상으로 파괴시험 등을 통한 경량화 알고리즘 추가연구가 필요하며, 최적화 결과를 충족시 키기 위한 생산공법의 개선에 관한 연구 또한 뒤따라야 한다.

\section{후기}

본 연구는 교육부 재원으로 한국연구재단의 지원을 받아 수 행된 기초연구사업(NRF-2017R1D1A3B03032051)과 2019년 해양 수산부 재원으로 해양수산과학기술진흥원의 지원에 의해 이루 어졌으며 이에 감사드립니다.

\section{References}

Han Z.Q., Jang, J.W., Noh, J.K., Oh, D.K., 2018. A Study on Material Properties of FRP Laminates for a Composite Fishing vessel's Hull. Proceedings of KSPE Spring Conference, 113-113.

ISO (International Organization for Standardization), 2008. ISO 12215-5 : Small craft - Hull Construction and Scantlings Part 5: Design Pressures for Monohulls, Design Stresses, Scantlings Determination. ISO, Switzerland.

Joung, T.H., Kang, S.G., Lee, J.K., An, J.G., 2018. Latest Progress on the IMO Regulation of the Green House Gas (GHG) Reduction. Bulletin of the Society of Naval Architects of Korea, 55(4), 48-54.

KOMSA (Korea Maritime Transportation Safety Authority), 2019. Standard of Construction and Equipment for the Less Than 10 Gross Tonnage of Small Fishing Vessels.

LR (Lloyd's Register) 2018. Rules \& Regulations for the Classification of Special Service Crafts.

MOF (Ministry of Oceans and Fisheries of Republic of Korea), 2016. Statistics of Registered fishing Vessel (1992 2016).

Oh, D.K., 2019. Marine Composites, FRP Vessels and Eco-friendly Design. The Society of Naval Architects of Korea Webzine, [Online] Available at: <http://www.snak.or.kr/newsletter/ webzine/news.html?Itemboard21\&modeview\&s_catgAugust $\%$ 2C+2019\&s_t1\&No645> [Accessed August 2019].

Oh, D.K., Han, Z.K., Noh J.K., 2018a. Light-Weight Design of 11 m-CFRP High Speed Craft Using Laminates Weight Optimization Method for Composite Ship Structures. Marine Technology, 5(345), 77-84.

Oh, D.K., Jung, S.H., Jeong, S.H., 2018b. Effect of a Lightweight Hull Material and an Electric Propulsion System on Weight Reduction : Application to a 45ft CFRP Electric Yacht. Journal of The Korean Society of Marine Environment \& Safety, 
24(6), 818-824. https://doi.org/10.7837/kosomes.2018.24.6.818

Oh, D.K., Lee, D.K., Kang, G.M., Ryu, C.H., Noh, J.K., 2014. Comparative Study of Rules of ISO 12215 and International Classification Society for Structural Design of CFRP Cruise Boat. Journal of Ocean Engineering and Technology, 28(1), 77-84. https://doi.org/10.5574/KSOE.2014.28.1.077

Oh, D.K., Lee, D.K., Jeong, S.H. 2019. Environmental Impact Evaluation on Lightweight Structure Design of a Composite Ship by LCA (Life Cycle Assessment). Jounral of Korean Society for Precision Engineering, 36(9), 875-881. http://doi.org/
10.7736/KSPE.2019.36.9.875

RIMS (Research Institute of Medium \& Small Shipbuilding) 2006. Design Drawings of GT 9.77 Ton Fishing Boat.

RINA (Registro Italiano Navale) 2013. Rules for the Classification of Pleasure Yacht Part B - Hull and Stability.

Song, J.H., Oh, D.K., 2016. Lightweight Structure Design for composite Yacht with Optimum Fiber Mass Content. Proceedings of International SAMPE Symposium and Exhibition, Long Beach CA. 